\title{
A compreensão do repouso e do movimento, a partir de referenciais observacionais não visuais: análises qualitativas de concepções alternativas de indivíduos portadores de deficiência visual total
}

Eder Pires de Camargo Faculdade de Ciências, UNESP - Cx. Postal 473, 17033-360 Bauru, SP e-mail - camargoep@ig.com.br Luís Vicente de Andrade Scalvi Departamento de Física - Faculdade de Ciências, UNESP -Cx. Postal 473, 17033-360 Bauru, SP

\section{Resumo:}

As limitações postas pela deficiência visual aos seus portadores não devem constituir obstáculos intransponíveis para que aprendam conteúdos científicos de física. Procedimentos educacionais a serem adotados, devem objetivar a efetivação de um processo de continuidade com os conhecimentos que o sujeito já possui acerca de sua realidade e de ruptura entre essa realidade e o senso comum, em direção ao conhecimento científico. Discutiremos neste texto, uma análise das concepções alternativas de repouso e movimento, encontradas junto a um grupo de seis sujeitos cegos (Camargo, 2000). Pretendemos que tais concepções, bem como sua análise, forneçam subsídios à elaboração de atividades de ensino desse conceito, atividades estas que não sejam fundamentadas em referenciais observacionais visuais e que colabore com o ensino de física do aluno cego, visto que, todos são capazes e competentes para aprender desde que sejam proporcionadas condições adequadas, considerando-se características típicas do aprendiz e do conteúdo a ser ensinado.

\section{I- Introdução: O ensino de física e os portadores de deficiência visual: Uma questão pouco explorada:}

A análise da bibliografia especializada sobre o Deficiente Visual, mostrou que seu desenvolvimento e aprendizagem são definidos a partir de padrões adotados para os videntes. Verificou-se que o "conhecer" esperado na educação do Deficiente Visual tem como pressuposto o "ver" e que, portanto, não se leva em conta as diferenças de percepção entre o Deficiente Visual e o vidente (Masini, 1994). Não obstante, tomando-se por base um referencial construtivista, o ensino de Física sob a óptica tradicional da forma em que se apresenta, tornase inviável ao portador de deficiência visual, pois enfoca a Física descontextualizada, desconsidera as concepções alternativas dos alunos e não tem por objetivo trabalhar com questionamentos conceituais (Brown e Clement, 1987).

Como exemplos apresentam-se os trabalhos de Linn e Thier (1975), Baughman e Zollman (1977), Weems (1977), e Sevilla et. al. (1991) que contribuem de uma certa forma à questão da preocupação com o ensino de Física à pessoas cegas, trazendo basicamente uma tentativa de adaptar materiais de laboratório no ensino dessa ciência à tais sujeitos, contudo, em nenhum momento esses trabalhos apresentaram qualquer discussão referente às concepções alternativas dos Deficientes Visuais. Fatos como estes devem-se segundo Masini (op. cit.) à 
desatenção à predominância da visão ou àquilo que ficou encoberto pela familiaridade, oculto pelo hábito, linguagem e senso comum numa "cultura de videntes".

Merleau-Ponty afirma que cada um sabe do mundo a partir de sua observação pessoal ou de sua experiência, sem a qual os símbolos da ciência nada significariam (apud. Masini, 1994). Segundo Silva (2000), a observação das descrições de fenômenos feitas com palavras do cotidiano por indivíduos cegos, revela uma "consciência ingênua", e é uma das condições para se chegar ao fenômeno (aquilo que se mostra), pois é uma consciência anterior a qualquer classificação ou explicação.

Em relação às concepções alternativas de pessoas videntes sobre repouso e movimento dos objetos, um grande número de estudos foram realizados nas últimas três décadas (Eckstein e Shemesh, 1993). Como resultado desses trabalhos, apresenta-se a constatação da não convergência entre as visões dos estudantes e o pensamento científico atual (Twigger, 1994). Pode-se analisar o problema de acordo com uma abordagem construtivista, considerando-se alguns pontos, dentre eles, a necessidade por parte dos estudantes de compreender o mundo ao seu redor, necessidade que produz análises e interações sensoriais e sociais, que resultam no surgimento das referidas concepções (Lochhead e Dufresne, 1989).

Um outro aspecto a ser ressaltado, é o de que muitas das idéias propostas por antigos filósofos acerca do movimento, se mostram bastante presentes na maneira de pensar de pessoas não peritas em Física (Cohen, 1967). Como aponta Peduzzi (1996), em termos didáticos e tendo em vista a construção do conhecimento do aluno, parece não apenas inevitável como salutar o estabelecimento de algumas analogias entre a lei de movimento de Aristóteles e certas concepções alternativas mantidas por estudantes de qualquer grau de escolaridade sobre força e movimento. Dessa forma, de acordo com o referencial construtivista, há a necessidade por parte dos estudantes de uma análise de suas próprias concepções, a fim de que possam ser questionadas e substituídas por novas mediante sua ineficácia.

Robin e Ohlson (1989), afirmam que as mudanças conceituais em ciências, não podem ser compreendidas sem o conhecimento dos conteúdos e das estruturas das concepções alternativas, que por sua vez, servirão de referencial para a construção de atividades de ensino. Cabe observar, que na literatura especializada, usou-se por muito tempo o termo "mudança conceitual" (Posner et al., 1982; Driver, 1989; Santos, 1991; Villani, 1992 e Carvalho, 1994), no sentido de buscar substituir as ditas concepções alternativas, por conceitos mais aceitos pela Ciência estabelecida. Contudo, as investigações da área (por exemplo: Gunstone et al., 1988; McDermott, 1991; Scott, 1993) mostraram a dificuldade de realizar tal intento. Nesse sentido, alguns autores (Duit, Goldberg e Niedderer, 1991; Silva e Latouff,1996 etc.) assumiram uma posição mais modesta, e passaram a empregar o termo "crescimento conceitual", no sentido de buscar-se melhorar as explicações dos alunos, já que a idéia de mudança, guarda um radicalismo difícil de conseguir.

Sendo assim, o presente artigo apresenta uma análise das concepções alternativas de repouso e movimento de um tipo particular de estudante, o deficiente visual total. Pretende-se que tais resultados possam subsidiar a elaboração de atividades de ensino de Física para portadores de deficiência visual, tendo a perspectiva de busca de melhoria nas concepções de repouso e movimento destes. Deste modo, retira-se o ensino do foco de perspectivas 
exclusivamente visuais, valorizando-se outros aspectos da interação do homem com o mundo físico, aspectos estes que deverão servir de subsídios para a elaboração de tais atividades.

\section{II- Principais Relações entre concepções alternativas e Conceitos da Física pré newtoniana:}

Como apontam os estudos de Clement (1979), Minstrell (1982), Watts (1983), Gardner (1986), há uma tendência de ocorrer convergências entre conceitos pré newtonianos, e concepções alternativas de pessoas não peritas em Física, acerca de questões relacionadas ao repouso e movimento dos objetos. Concepções alternativas como: há a necessidade de uma força para causar e manter o movimento, ou a compreensão da gravidade como propriedade particular do objeto, parecem de acordo com Cohen (op. cit.) caracterizar a compreensão de movimento de individuos não especialistas no tema.

Tais concepções são segundo McCloskey, et. al. (1980), tão antigas quanto as de Aristóteles, cujas explicações envolvidas para o movimento de objetos como uma carroça, eram relacionadas ao conceito de que a todo corpo que se move, associa-se um movedor, e as explicações para o movimento de queda de uma pedra, relacionadas ao conceito de que há uma tendência de objetos sólidos (mesmo material da Terra) cair para seu lugar natural de descanso, a superfície da Terra.

No entanto, no que se refere ao movimento de projéteis, a concepção alternativa mais expressa parece convergir ao conceito de impetus. Segundo tal conceito, o movimento de uma bola é explicado devido à ação de uma força impressa ao objeto, mesmo após este não manter mais contato com o agente da força. A antiperistasis aristotélica é rejeitada. Neste conceito, o movimento de um projétil se dá não pela ação de uma força impressa, mas sim, pela ação de uma força exercida pelo ar que desloca o objeto para a frente após ter servido de resistência para o mesmo. Portanto, as experiências dos indivíduos em relação ao movimento de projéteis, detêm analogias com o conceito ou idéia de força impressa de Hiparco/Filoponos e com a teoria do impetus de Buridan e seus seguidores (Peduzzi, op. cit.).

Não obstante, as concepções alternativas de senso comum que são incompatíveis com as teorias científicas vigentes, não são enganos arbitrários ou triviais, pois surgem de experiências pessoais. Estas concepções, comuns entre os indivíduos, foram intensamente defendidas pelos principais intelectuais da fase pré-newtoniana. Se a superação das visões de mundo, desde Aristóteles até Galileu representou significativo obstáculo na história da Ciência, não deveriam haver por parte dos educadores, surpresas no reconhecimento de que tal superação representa grande barreira para os estudantes ainda hoje (Lemeignan e WeilBarrais, 1994).

Dessa forma, apresentar-se-á abaixo, uma síntese da relação entre o pensamento prénewtoniano e concepções alternativas de pessoas videntes, estabelecida por Halloun, e Hestenes, (1985), que procuraram descrever e generalizar algumas concepções. Tal síntese, subsidiará a análise das concepções alternativas de pessoas cegas, posteriormente apresentada. 
1) O movimento é causado pela ação de uma força aplicada ao objeto por um agente externo ou pela ação da "gravidade", que pode ser compreendida como uma propensão intrínseca ao objeto de cair.

2) O movimento é mantido por uma ação contínua de uma força ou "gravidade", ou por uma força interna ao objeto (impetus).

3) Os fatores que se opõem ao movimento podem ser descritos como sendo, resistência intrínseca (peso ou massa) do objeto, resistência do meio que o envolve, bem como obstáculos em geral. Cabe lembrar que não há distinção por parte do senso comum entre peso e massa.

4) A terceira lei de Newton se mostra incompatível com as concepções do senso comum. Quando dois objetos de massas consideravelmente diferentes colidem entre si, o de maior massa exerce uma maior força no de menor massa.

5) Existem duas analogias para o princípio de soma vetorial. A primeira refere-se à determinação do sentido do movimento de um objeto que sofre ação de forças paralelas, ou seja, o sentido do movimento é determinado pelo sentido da maior força que age no objeto, isto, considerando é claro, que o objeto sofre ação de forças de mesma direção e sentidos opostos. A segunda analogia refere-se à determinação da direção e sentido do movimento de um objeto que sofre a ação de forças não paralelas. Neste caso, a direção e o sentido do movimento do objeto, são determinados por uma espécie de "meio termo" das forças aplicadas nele.

6) Uma força aplicada é sinônimo de empurrar ou puxar. Para alguns, apenas seres vivos são reconhecidos como "agentes de força".

7) O efeito de uma força aplicada está comumente caracterizado pelos princípios causais seguintes:

- Uma força não pode mover um objeto a menos que seja maior que o peso do objeto (peso não é distinto de massa).

- Uma força constante produz uma velocidade constante.

- Aceleração se deve à ação de uma força crescente

- O efeito de uma força constante, é limitado e depende de sua magnitude. Tal limitação pode ser descrita de dois modos:

a) a força se extingue devido ao seu consumo pelo movimento ou sua dissipação por agentes resistivos.

b) Uma força $F$, acelera um objeto até que ele atinja uma certa velocidade crítica proporcional a F que o objeto mantém independente da força estar sendo ou não aplicada.

- Uma força de longo alcance (ação a distância) deve ser transmitida por uma corda que conecta o objeto ao agente. Forças de longo alcance não podem agir em objetos que estejam localizados no vácuo.

8) Uma força interna ou impetus, mantém o movimento de objetos independentemente de agentes externos.

Segundo as observações de Clement (1982), existe um princípio entre os estudantes de que há uma força na mesma direção do movimento de um objeto. Nos itens 9, 10 e 11, tal princípio é relacionado.

9) Um impetus pode ser fornecido ao objeto, pela ação de uma força externa, além de poder ser transmitido de um objeto para outro. 
10) O impetus de um objeto é proporcional à sua massa e velocidade como expresso na equação $(F=m v)$.

11) O conceito de impetus pode ser semelhante ao conceito de uma força externa aplicada

12) A resistência se opõe a uma força aplicada ou consome o impetus de um objeto em movimento. Os tipos seguintes de resistência, não são geralmente distintos.

a) Inércia (peso ou massa) é uma resistência intrínseca do objeto ao movimento

b) Fricção devido ao contato entre o objeto e uma superfície sólida

c) A resistência em um fluido, depende da densidade desse fluido como também do tamanho, forma e peso do objeto.

13) Obstáculos podem redirecionar ou interromper um movimento, mas não podem ser agentes de uma força aplicada

14) A gravidade é encarada como uma propensão que os objetos têm para cair, de acordo com esta concepção, a gravidade não é necessariamente entendida como uma força, no entanto, os princípios causais para forças aplicadas relacionados acima, podem também serem atribuídos à gravidade.

15) Quanto maior o peso (massa) de um objeto, maior será sua velocidade de queda.

\section{III- METODOLOGIA}

De acordo com a perspectiva de investigação aqui apresentada, a realização de entrevistas mostrou-se um instrumento fundamental para a coleta dos dados desejados. A liberdade de percurso deste instrumento de obtenção de informações está associada mais especificamente à entrevista semi estruturada, que se desenrolou a partir de um esquema básico, porém não aplicado rigidamente junto ao grupo de deficientes visuais, permitindo que fossem feitas as necessárias correções, esclarecimentos e adaptações. Durante a elaboração das questões, utilizou-se um roteiro que guiou a entrevista através dos tópicos principais a serem cobertos. Esse roteiro seguiu uma certa ordem lógica, ou seja, os assuntos foram abordados dos mais simples aos mais complexos.

Cada sujeito entrevistado foi colocado mediante quatro situações problemas, sendo que, dentro de cada situação eram feitas questões que tinham por objetivo traze-los à reflexão de ocasiões voltadas ao movimento dos corpos. A preocupação principal não era a de obter a resposta para tais questões, mas sim, a de gerar um diálogo com o entrevistado sobre movimento e através desse diálogo, procurar identificar suas concepções alternativas sobre o tema. Procurou-se conversar com os sujeitos através da utilização de expressões não técnicas evitando desta forma o emprego de termos como força, gravidade, pressão, etc. No caso do sujeito se referir a um desses termos, aproveitava-se para questioná-lo sobre seu significado e a partir disso passava-se a usá-lo ou não. Outros objetos de exploração eram os exemplos que livremente os sujeitos expunham em suas explicações, sendo que a maioria deles foram extremamente úteis para análise.

Desta forma, esta pesquisa se efetivou seguindo um plano de trabalho, dividido em 04 etapas, listadas a seguir: 
ETAPA 01 - Seleção dos sujeitos: Participaram desta pesquisa sujeitos adultos cegos de nascença ou que perderam a visão na infância, e que não possuíam deficiência mental e/ou auditiva. Cabe ressaltar que todos os sujeitos eram alunos da instituição Lar Escola Santa Luzia para Cegos, localizada na cidade de Bauru. O número de alunos desta instituição era na ocasião de vinte e cinco, sendo que desses, seis se enquadraram nos critérios estabelecidos acima e os outros dezenove não apresentavam as características necessárias para a pesquisa. Dos seis sujeitos selecionados, quatro eram cegos de nascença, dois perderam totalmente a visão na infância, até os cinco anos. Abaixo, encontram-se disponíveis algumas características peculiares de cada sujeito:

Sujeito 1: Cego de nascimento, 38 anos, cursou o ensino fundamental e médio em escola pública, era na ocasião universitário e cursava o segundo ano de Fisioterapia.

Sujeito 2: Cego de nascimento, 42 anos, concluiu o ensino fundamental em escola pública.

Sujeito 3: Cego de nascimento, 16 anos, na ocasião era estudante da primeira série do ensino médio em escola particular.

Sujeito 4: Perdeu totalmente a visão aos três anos de idade, 23 anos, concluiu o ensino fundamental em escola pública.

Sujeito 5: Perdeu totalmente a visão aos cinco anos de idade, 32 anos, freqüentou a escola regular pública até a $5^{\underline{a}}$ série.

Sujeito 6: Cego de nascimento, 45 anos, nunca cursou a escola pública regular, vindo ser alfabetizado na própria instituição "Lar Escola Santa Luzia" através do sistema braille.

ETAPA 02 - Elaboração do questionário e realização das entrevistas: Nesta etapa, quatro questões problemas abertas foram abordadas, sendo que a partir de cada questão se estabeleceu um diálogo com o entrevistado, onde sub-questões elaboradas previamente e/ou extraídas de artigos especializados em concepções alternativas e exemplos propostos pelos sujeitos, foram enfocados.

\section{Situação 1- Repouso dos objetos:}

1.1- O que faz com que o livro fique em repouso sobre a mesa?

1.2- Coloca-se um livro sobre a mão esticada do sujeito. Coloca-se mais de um livro na mão esticada do sujeito. O que você fez para que o livro permanecesse parado sobre sua mão? Para você, o que é força? Você acha que a mesa poderia exercer uma força no livro? (Minstrell, 1982).

\section{Situação 2 - Movimento horizontal dos objetos:}

2.1- Com as mãos, aplica-se ao livro uma força paralela ao plano: O que acontecerá quando não houver mais o contato entre a mão e o livro?

2.2- Por que os objetos se movem?

2.3- Você precisa empurrar ou puxar um objeto para que ele se movimente sempre com a mesma velocidade? 
2.4- Por que alguns objetos continuam se movendo por um certo tempo depois de você ter deixado de empurrá-los?

2.5- Por que objetos param de se mover?

2.6- Se você empurra um livro e uma bola de metal com a mesma força, qual irá mais longe? Por que?

2.7- Poderia existir uma situação em que um objeto em movimento continuasse em movimento com a mesma velocidade embora não haja nada empurrando-o ou puxando-o? (Lochhead e Dufresne, 1989)

Situação 3 - Queda dos objetos:

3.1- Você tem em suas mãos uma pedra. O que acontecerá se você abandoná-la? Por que? E se você lançá-la para cima?

3.2- Por que objetos caem?

3.3- Se você joga uma pedra para cima, o que acontece com ela? Por que?

3.4- Você tem em suas mãos uma esfera de metal e uma folha de papel aberta. Se você abandoná-las da mesma altura, quem chegará primeiro ao solo? Por que? (Hise, 1988)

3.5- Imagine que do alto de um prédio de 50 andares são abandonados dois objetos no mesmo instante. Um dos objetos é uma grande pedra de uma tonelada e o outro uma pequena pedra de um quilograma. Qual deles chegará primeiro ao solo? Por que? (Robin e Ohlsson, op. cit.).

3.6- Lembra-se da questão 3.4 (folha de papel aberta e esfera de metal)? Imagine agora que a folha de papel esteja amassada de tal forma que pareça com uma esfera. Qual das duas chegará primeiro ao solo se forem abandonadas no mesmo instante e da mesma altura? Por que?

\section{Situação 4 - Trajetória dos objetos:}

4.1- Considere um tubo cilíndrico não encurvado colocado sobre uma mesa horizontal. Coloca-se dentro do tubo uma esfera rígida de metal cujo diâmetro é apenas um pouco menor do que o diâmetro do tubo, a fim de que possa se mover livremente dentro do tubo. Você empurra a esfera. Qual será o caminho percorrido por ela após abandonar o tubo?

4.2- Considere agora que o tubo seja encurvado. Qual será o caminho descrito pela esfera ao abandonar o tubo?

4.3- Você prende uma esfera a um fio rígido e a gira sobre sua cabeça. Explique qual será o caminho descrito pela esfera se você soltar o fio (McCloskey, et. al., op. cit.).

A análise das respostas fornecidas pelos deficientes visuais a tais questionamentos, procurou não desprezar qualquer manifestação (oral ou gesticulada), pois estas poderiam apresentar dados indispensáveis no que se refere às concepções alternativas (Masini, op. cit. ), por isso, o registro das entrevistas em fitas de vídeo, tornou-se fundamental no processo.

ETAPA 03 - Identificação das idéias dos sujeitos: Esta etapa se caracterizou pela transcrição das entrevistas. Cada linha, no ato da transcrição, foi enumerada a fim de uma melhor localização de idéias fornecidas pelos sujeitos sobre os temas já citados. Define-se por idéias dos sujeitos, trechos extraídos do texto transcrito que de acordo com a interpretação do pesquizador fornece informações sobre como o sujeito compreende questões relacionadas ao 
tema pesquisado (Robin e Ohlsson, op. cit.). As idéias foram caracterizadas pela numeração das linhas do referido texto.

É importante ressaltar que todas as idéias dos sujeitos não estão explicitadas aqui, pois a disposição das idéias ocuparia um grande espaço, o que inviabilizaria a exposição deste texto. Contudo, no fragmento abaixo retirado da entrevista transcrita de $S_{1}$, tem-se um exemplo de como as idéias dos sujeitos foram identificadas. Os trechos (linhas 8 e 9), (linha 12), (linhas 14 e 15) e (Linhas 17, 18 e 19), referem-se respectivamente a idéias identificadas do sujeito e posteriormente, juntamente com idéias de outros sujeitos, interpretadas, generalizadas e categorizadas como uma determinada concepção alternativa. Foram utilizadas as siglas $\mathrm{C}_{\mathrm{n}}$ para identificar a concepção alternativa $n, S_{k}$ para identificar o sujeito $k$, e $E$ para identificar $o$ entrevistador que é um dos autores deste artigo.

1 E: Vamos começar a primeira fase de questões, eu vou dar um objeto para você. Você 2 poderia me dizer o que é isso?

$3 \mathrm{~S}_{1}$ : Isto é um livro.

4 E: Exatamente. Vamos colocá-lo aqui sobre a mesa. Você poderia me dizer como ele 5está?

$6 S_{1}$ : Repouso.

$7 \quad$ E: O que é repouso para você?

$8 \quad S_{1}$ : Repouso é quando a gente coloca um objeto sobre um lugar e o deixa sem mexer 9nele.

10 E: Quer dizer que ele está em repouso? Ele não está mexendo? É o oposto de estar 11mexendo?

$12 \mathrm{~S}_{1}$ : Exatamente, é não mexer. Está paradinho ai, quietinho.

13 E: Por que você acha que as coisas ficam em repouso, especificamente esse livro?

$14 S_{1}$ : É Porque ele não tem condições de sair do lugar em que ele se encontra, se alguém 15 não tocar nele, não levá-lo para onde ele deseja.

16 E: Você poderia explicar melhor isso?

$17 \mathrm{~S}_{1}$ : O livro não consegue andar, o livro é um objeto, ele não é gente, não é como nós 18 que conseguimos nos locomover, ele não tem condições de se locomover se nós não o 19apanharmos de um lugar e levarmos para onde nós queremos que ele vá.

ETAPA 04 - Interpretação e generalização das idéias em termos de concepções alternativas: Nesta etapa buscou-se interpretar as idéias dos sujeitos de acordo com semelhanças conceituais, e agrupá-las em termos de concepções alternativas, ou seja, uma concepção alternativa resulta do agrupamento de idéias do mesmo e/ou de outros sujeitos, que possuem de acordo com a interpretação do pesquisador, a mesma característica conceitual. Através disso, se eliminou os erros e ambigüidades extremamente comuns na linguagem falada e pôde-se relacionar e generalizar o mesmo tipo de característica conceitual expressa nas idéias do grupo de sujeitos.

Dessa forma, para $S_{1}$ identificou-se 102 idéias que foram interpretadas e agrupadas em 18 concepções alternativas. Para $S_{2} 0$ número de idéias foi de 97, interpretadas e agrupadas em 25 concepções. Para $S_{3}$ esses números são respectivamente de 72 idéias e 22 concepções. Já 
para $S_{4}$ obteve-se 62 idéias e 21 concepções. Para $S_{5}$ o número de idéias foi de 56 enquanto o número de concepções alternativas 20 . Finalmente para $S_{6}$ obteve-se respectivamente 62 idéias e 14 concepções.

Os fragmentos abaixo indicam várias idéias e exemplificam como tais idéias, do mesmo e de diferentes sujeitos, foram interpretadas e agrupadas como sendo a concepção alternativa $C_{1}$. O mesmo procedimento foi adotado para a identificação do restante das concepções alternativas, e tal procedimento encontra-se explicitado na íntegra em Camargo (op. cit.).

$\mathrm{S}_{1}$ : Repouso é quando a gente coloca um objeto sobre um lugar e o deixa sem mexer nele.

$\mathrm{S}_{1}$ : Exatamente, é não mexer. Está paradinho ai, quietinho.

$\mathrm{S}_{2}$ : Ele está em repouso, ele está deitado sobre a mesa.

$\mathrm{S}_{2}$ : repouso é uma posição inerte, parada.

$\mathrm{S}_{2}$ : parado é contrário dos movimentos.

$\mathrm{S}_{3}$ : Parado é o que permanece no mesmo lugar.

$\mathrm{E}$ : Por que ele parou? $\mathrm{S}_{4}$ : Porque ele parou de se movimentar.

$\mathrm{S}_{5}$ : Ele está parado, deitado sobre a mesa.

E: Por que você acha que o livro fica parado sobre a mesa? $\mathrm{S}_{6}$ : Porque não tem jeito de andar

$\mathrm{C}_{1}$ - Um objeto se encontra em repouso quando está parado em um determinado local e sem que ninguém ou alguma coisa o empurre ou o puxe, ou mexa com ele.

\section{IV- Concepções alternativas de pessoas cegas sobre repouso e movimento:}

Portanto as 47 concepções alternativas identificadas encontram-se abaixo. Elas estão separadas obedecendo o critério de grupo de sujeitos que as expressaram. Uma outra maneira de identificá-las, é através de semelhanças conceituais que as mesmas estabelecem ou não com os modelos aristotélico de movimento, e/ou do ímpetos. Tal classificação obedece os critérios que se seguem.

Concepções alternativas aristotélicas (A): Identificadas pela sigla A, são as concepções que mantém analogias ao modelo aristotélico de movimento, ou seja, obedecem os princípios de que a todo corpo móvel associa-se um movedor que mantém constante contato com o que se move (movimento Forçado ) e o princípio que explica a queda de objetos sólidos (movimento Natural).

Concepções alternativas de Impetus (I): Identificadas pela sigla I, são concepções que mantêm analogias à teoria de força impressa desenvolvida pelos críticos de Aristóteles dos quais destacam-se Philoponus (século V) e Buridan (século XIV). O movedor nesta teoria, não é entendido como um "ente físico", o que faz com que seja discordante do conceito de antiperistasis (FRANKLIN, 1978).

Concepções alternativas parcialmente aristotélicas (P.A): Identificadas pela sigla P.A, são concepções que de uma certa forma obedecem os princípios aristotélicos de movimento, no entanto, utilizam elementos como o ar ou a "gravidade" como movedores ou então, utilizam-se de princípios não aristotélicos como o de que durante a subida, a velocidade de uma bola aumenta, ou o de que a velocidade de chegada é superior à velocidade de saída de uma bola que é lançada para cima. 
Concepções alternativas discordantes do modelo aristotélico de movimento (D.A): Identificadas pela sigla D.A, são concepções que são contrárias ao modelo aristotélico de movimento.

Concepções alternativas discordantes da teoria do impetus (D.I): foram enquadradas nesta categoria, principalmente as concepções que eram discordantes da teoria de impetus circular. Tais concepções foram identificadas pela sigla D.I.

Concepções alternativas sem conexão (S.C): Identificadas pela sigla S.C, estas concepções não mantêm qualquer analogia ao modelo aristotélico de movimento e/ou ao conceito de impetus.

\section{Concepções alternativas expressas por todos os sujeitos}

$A C_{1}$ - Um objeto se encontra em repouso quando está parado em um determinado local e sem que ninguém ou alguma coisa o empurre ou o puxe, ou mexa com ele.

$\mathrm{A} \mathrm{C}_{2}$ - Pelo fato do livro ser um objeto que não possui vida, ele não sairá do lugar em que se encontra a menos que alguém ou alguma coisa o leve para onde deseja.

$\mathrm{A}_{3}$ - Objetos sem vida como a mesa, não exercem forças no livro, ela apenas serve de obstáculo para que o livro não chegue ao chão.).

$\mathrm{A} \mathrm{C}_{4}$ - Quando eu seguro o livro com as minhas mãos ele não cai, porque eu, ser vivo, exerço uma força com o meu braço que é suficiente para impedir a queda do livro.

$\mathrm{A}_{5}$ - Os objetos se movimentam devido a ação de uma força, e esse movimento se dará na mesma direção e sentido da força.

$\mathrm{A}_{6}$ - Um objeto deixará de se mover quando a força deixar de ser aplicada sobre ele.

$\mathrm{A} \mathrm{C}_{7}$ - $\mathrm{O}$ motivo pelo qual objetos como a bola se movem mesmo sem o contato com 0 movedor, e outros como o livro não, é devido ao seu formato, seu peso, ou seu material.

$\mathrm{A}_{8}$ - Os objetos pesados caem, e os objetos leves vão para cima, porque é natural que seja assim.

$\mathrm{A} \mathrm{C}_{9}$ - O peso ou "gravidade" leva os objetos pesados para baixo.

$\mathrm{A} \mathrm{C}_{10}$ - Objetos mais pesados caem mais rapidamente que objetos leves.

$A C_{11}$ - Força ou energia é algo que os seres vivos são capazes de fazer ou exercer para impedir que um objeto chegue ao chão, ou para mudar um objeto do lugar, empurrando-o ou puxando-o.

$\mathrm{I}_{12}$ - Alguns objetos como um carrinho de fricção ou uma bola, continuam se movendo mesmo sem haver contato entre eles e o movedor (aquele que os colocou em movimento), pelo fato de que o movedor lhes transmite uma força que é responsável pela continuação do movimento e esse movimento se dará até que a força cesse.

$\mathrm{I}_{\mathrm{C}_{13}}$ - O formato de um cano interfere na trajetória de uma esfera após esta tê-lo abandonado.

\section{Concepções alternativas expressas por três sujeitos}

$A C_{14}$ - É impossível que um objeto se mova sempre com a mesma velocidade se alguma coisa não puxá-lo ou empurrá-lo. Expressa por $S_{2}, S_{3}$ e $S_{5}$. 
D.A $C_{15}$ - Os objetos mais leves chegam primeiro ao solo, porque é mais fácil para a "gravidade" empurrá-los para baixo. Expressa por $\mathrm{S}_{3}, \mathrm{~S}_{5}$ e $\mathrm{S}_{6}$.

S.C $\mathrm{C}_{16}$ - A folha de papel amassada é mais pesada que a folha de papel aberta, ou seja, 0 formato interfere no peso dos objetos. Expressa por $S_{1}, S_{2}$ e $S_{3}$.

S.C $\mathrm{C}_{17}$ - Velocidade está relacionada com distância e tempo. Expressa por $\mathrm{S}_{2}, \mathrm{~S}_{3}$ e $\mathrm{S}_{5}$.

\section{Concepções alternativas expressas por dois sujeitos}

$\mathrm{A} \mathrm{C}_{18}$ - A altura que um objeto atinge quando lançado para cima depende da força do lançador. Expressa por $\mathrm{S}_{2}$ e $\mathrm{S}_{4}$.

D.I $C_{19}$ - Dependendo do valor da força aplicada na bolinha, ela poderá descrever trajetórias encurvadas ao abandonar o cano reto ou retilínea ao abandonar o cano torto. Expressa por $\mathrm{S}_{1} \mathrm{e}$ $\mathrm{S}_{2}$.

D.I $C_{20}$ - A velocidade tangencial de uma esfera que gira amarrada ao um barbante não influencia em sua trajetória quando esta é solta ou quando o barbante se rompe, a trajetória desta esfera será retilínea na vertical e de cima para baixo. Expressa por $S_{1}$ e $S_{2}$.

D.I $\mathrm{C}_{21}$ - O formato do cano não interfere na trajetória de uma esfera quando esta o abandona. Sua trajetória será sempre retilínea. Expressa por $\mathrm{S}_{5}$ e $\mathrm{S}_{6}$.

S.C $\mathrm{C}_{22}$ - Existem várias naturezas de forças, como por exemplo a força humana e a energia elétrica. Expressa por $\mathrm{S}_{1}$ e $\mathrm{S}_{2}$.

S.C $\mathrm{C}_{23}-\mathrm{A}$ velocidade constante é aquela que permanece sempre a mesma. Expressa por $\mathrm{S}_{1} \mathrm{e}$ $\mathrm{S}_{2}$.

S.C $\mathrm{C}_{24}$ - O formato dos objetos não influencia em sua massa. Exemplo: folha de papel aberta e folha de papel amassada. Expressa por $S_{1}$ e $S_{3}$.

\section{Concepções alternativas expressas por um sujeito}

$\mathrm{A} \mathrm{C}_{25}$ - Se uma bola e uma pedra forem atiradas numa piscina com água, a pedra afundará e a bola não, pelo fato da pedra ser mais pesada que a água e a bola, não. Expressa por $\mathrm{S}_{2}$.

$\mathrm{A}_{26}$ - o Fato da superfície de contato com o objeto que se move, ser lisa ou áspera, influencia na duração do movimento e na distância percorrida. Expressa por $\mathrm{S}_{3}$.

$\mathrm{A}_{27}$ - Objeto sem vida, só se movimentam devido à ação de uma força externa. Expressa por $\mathrm{S}_{4}$.

$\mathrm{A} \mathrm{C}_{28}$ - O formato de objetos de mesma massa influencia no tempo de queda. Expressa por $\mathrm{S}_{5}$. $\mathrm{I}_{29}$ - A trajetória de uma esfera que após se desprender de um barbante que a fazia girar, é circular e na vertical de cima para baixo. Expressa por $\mathrm{S}_{3}$.

P.A $\mathrm{C}_{30}$ - O motivo pelo qual uma bolinha de aço vai mais longe que uma bolinha de isopor, é pelo fato da bolinha de aço ser mais lisa do que a de isopor. Expressa por $\mathrm{S}_{3}$.

P.A $\mathrm{C}_{31}$ - $\mathrm{O}$ ar empurra as coisas para baixo. Expressa por $\mathrm{S}_{3}$.

P.A $\mathrm{C}_{32}$ - Seres vivos, exceto os que possuem algum defeito físico, como paralisia, movimentam-se com suas próprias forças. Expressa por $\mathrm{S}_{4}$.

P.A $\mathrm{C}_{33^{-}}$Uma bolinha que está girando amarrada a um barbante cairá um pouco pra frente quando for solta. Expressa por $\mathrm{S}_{4}$. 
P.A $\mathrm{C}_{34}-\mathrm{Na}$ Terra as coisas caem, no espaço, flutuam. Expressa por $\mathrm{S}_{5}$.

P.A $\mathrm{C}_{35}$ - Quando um objeto é lançado para cima, durante a subida, sua velocidade aumenta de tal forma que quando ele retorna ao lugar de onde saiu, sua velocidade é muito maior do que quando foi lançado. Expressa por $\mathrm{S}_{2}$.

P.A $\mathrm{C}_{36}-\mathrm{A}$ gravidade é como uma força que empurra os objetos de cima para baixo. Expressa por $\mathrm{S}_{2}$.

D.A $\mathrm{C}_{37}$ - "Velocidade" e "força" são coisas parecidas. Expressa por $\mathrm{S}_{4}$.

D.A $\mathrm{C}_{38}$ - Se não existisse a gravidade, os objetos iriam subir. Expressa por $\mathrm{S}_{3}$.

D.A $C_{39}-A$ Terra é como um ímã que atrai para si os objetos à distância Expressa por $S_{5}$.

D.A $\mathrm{C}_{40}$ - $\mathrm{A}$ bola e a folha de papel aberta, cairão juntas, quando soltas da mesma altura ao mesmo tempo. Expressa por $\mathrm{S}_{6}$.

S.C $\mathrm{C}_{41}$ - Uma bolinha, ao abandonar o cano reto ou torto, terá uma trajetória aleatória, pois não há nada que a faça permanecer em linha reta. Expressa por $S_{3}$.

S.C $\mathrm{C}_{42}-\mathrm{A}$ gravidade é uma força do ar. Expressa por $\mathrm{S}_{4}$.

S.C $\mathrm{C}_{43}-\mathrm{A}$ gravidade não age em objetos como pássaro ou avião. Expressa por $\mathrm{S}_{4}$.

S.C $\mathrm{C}_{44}-\mathrm{A}$ folha de papel amassada é mais leve que a folha de papel aberta. Expressa por $\mathrm{S}_{4}$.

S.C $\mathrm{C}_{45}$ - A folha de papel aberta e a folha de papel amassada tem o mesmo peso. Expressa por $S_{5}$.

S.C $\mathrm{C}_{46}$ - No espaço, ao contrário da Terra, os objetos se repelem, como ímãs de mesma polaridade, próximos. Expressa por $\mathrm{S}_{5}$.

S.C $\mathrm{C}_{47}$ - Força e energia são a mesma coisa. Expressa por $\mathrm{S}_{2}$.

Das quarenta e sete concepções alternativas obtidas, dezessete são concordantes com a teoria aristotélica de movimento $(A)$, sete são parcialmente concordantes com essa teoria (P.A) e três são concordantes com a teoria do impetus (I); cinco convicções são discordantes da teoria aristotélica (D.A), três são discordantes da teoria do impetus (D.I.), E doze não mantém conexão com essas teorias (S.C). Das vinte e sete concepções que fazem parte do grupo das aristotélicas, impetus ou parcialmente aristotélicas, Treze foram expressas por todos os sujeitos, Uma concepção foi expressa por um grupo de três sujeitos, uma outra por um grupo de dois e doze concepções foram expressas individualmente pelos sujeitos.

O grupo formado por todos os sujeitos, sem exceção, expressou apenas concepções classificadas como aristotélicas e de impetus, sendo que as outras categorias de concepções alternativas, apareceram em maior proporção em relação às categorias de concepções alternativas aristotélicas e de impetus nos grupos de três e dois sujeitos como também nos grupos unitários.

Para o grupo de sujeitos, com exceção de $S_{4}$ e $S_{5}$, que perderam a visão até os três anos de idade e até os cinco anos de idade respectivamente, todos os outros eram cegos de nascença e portanto, as experiências sensoriais que esses indivíduos mantiveram com o mundo físico, nunca teve participação do estímulo visão. Apesar da ausência de experiências visuais, existia uma semelhança conceitual entre suas concepções alternativas, e os princípios de que há a necessidade de uma força de contato ou impressa, para se manter o movimento, e de que a queda dos objetos é algo natural. 
As concepções alternativas que são discordantes ou não mantém conexão com o modelo aristotélico e/ou de impetus, foram encontradas entre os seis sujeitos, entretanto, tais concepções destacam-se por serem comuns a grupos menores, grupos de três e de dois sujeitos, e também para grupos unitários. Essas concepções, geralmente referiam-se a algumas situações particulares vividas por cada sujeito, que eram provenientes de suas experiências individuais, como andar de avião, ou explicações ouvidas do professor sobre questões da Física enquanto freqüentaram a escola.

\section{V- Análise qualitativa das concepções alternativas obtidas:}

Serão analisadas neste tópico, algumas das concepções alternativas obtidas. Um dos aspectos enfatizados nas análises apresentadas, é o de quais são as implicações causadas pela cegueira nas concepções alternativas de repouso e movimento de indivíduos cegos. Dessa forma, busca-se identificar as relações entre tais concepções e as de indivíduos videntes, bem como, com conceitos da Física Pré Newtoniana.

De acordo com Halloun e Hestenes (1985), Aristóteles foi o primeiro a desenvolver sistematicamente formulações explícitas para concepções alternativas sobre fenômenos físicos e organizá-las em um sistema conceitual coerente. Ele, deste modo, preparou um caminho para uma crítica de tais concepções que contribuíram para o desenvolvimento da Física enquanto Ciência. No entanto, como aponta Koyré (1986), é necessário não reduzir a criteriosa Física aristotélica, à visão de senso comum, muito menos elaborada devido ao seu não interesse investigativo, pois ainda que não o seja matematicamente, a física aristotélica é uma teoria altamente elaborada, que transcende os fatos do senso comum que servem de base à sua elaboração. Desse modo, as análises apresentadas abaixo, não tem o objetivo de tal redução, mas sim, o de manter algumas analogias entre tais fatos, e alguns conceitos da Física aristotélica e/ou do impetus, conceitos estes que de acordo com Stinner (1994), estão "bem vivos" nas mentes das pessoas ainda hoje.

As concepções alternativas $\mathrm{C}_{1}, \mathrm{C}_{2}, \mathrm{C}_{3} \mathrm{e}_{4}$, expressam basicamente que estar em repouso é estar não sujeito à ação de forças. De acordo com os sujeitos que expressaram essas concepções, repousar não necessita de maiores explicações, já que para eles parece óbvio que objetos inanimados como um livro sobre a mesa (situação-1) permaneçam ali sem que algo os tire dali $\left(\mathrm{C}_{1}\right.$ e $\left.\mathrm{C}_{2}\right)$. Tais concepções alternativas Mantém de uma certa forma, analogias com a visão aristotélica de repouso dos objetos. Segundo esta abordagem, o repouso de um objeto não necessita de maiores explicações é a sua própria natureza que o explica (Koyré, op. cit.).

A concepção alternativa $\mathrm{C}_{3}$, afirma que objetos sem vida como uma mesa, não exercem forças, tais objetos apenas servem de obstáculo para que o livro não prossiga o seu movimento descendente. A experiência que foi realizada com os sujeitos, (questão 1.2) ou seja, a experiência de colocar vários livros sobre suas mãos estendidas, tinha o objetivo de pô-los em reflexão sobre questões relacionadas à ação de forças que agem no sentido de manter objetos em repouso. É evidente que cada sujeito necessitou fazer força com seu braço estendido a fim de segurar o livro $\left(\mathrm{C}_{4}\right)$, no entanto, a mesa de acordo com essa concepção, por não possuir vida, não poderia em hipótese alguma exercer uma força para cima no livro a fim de impedir 
que ele caísse $\left(\mathrm{C}_{3}\right)$. Tal concepção alternativa assemelha-se às encontradas nos trabalhos realizados com sujeitos videntes por Minstrell (op. cit.) e por Halloun e Hestenes (op. cit.).

No grupo de concepções alternativas $\left(C_{5}, C_{6}, C_{11}, C_{14}, C_{27}, C_{31}, C_{32}\right.$, e $\left.C_{36}\right)$, há uma justificação acerca dos motivos causadores do movimento de objetos como um livro, pois tais concepções afirmam que o motivo pelo qual um objeto se move é devido à ação de uma força e esse movimento terá fim assim que essa força deixar de atuar sobre o objeto. Tais concepções assemelham-se ao conceito de movimento forçado de Aristóteles. Para Aristóteles, movimento não natural só é possível quando se associa ao que se move, um movedor (o que aplica a força). Esta concepção alternativa para o grupo de sujeitos, é bastante relevante, pois a partir do momento em que a força aplicada ao livro cessa, o movimento do mesmo também cessa e como as pessoas que participaram das entrevistas eram cegas, uma das experiências que as levaram a expressar essas concepções, era tátil, ou seja, quando se empurrava o livro ele movimentava-se, e quando se retirava a mão do livro ele parava. Portanto segundo este princípio, para que haja movimento de objetos como um livro, é necessário que o que move e o que se movimenta estejam em permanente contato.

A concepção alternativa $C_{12}$, refere-se ao movimento de objetos que continuam a se mover mesmo após não haver mais o contato entre eles (movente) e o movedor (o responsável pelo início do movimento). Tal concepção, conforme aponta Peduzzi (op. cit.) bastante comum entre estudantes, é semelhante ao conceito de força impressa ou impetus proposto pelos críticos de Aristóteles. De acordo com esse conceito, o movimento cessará com a diminuição gradativa do impetus. Nos trechos abaixo, extraídos das entrevistas concedidas por $\mathrm{S}_{4}$ e $\mathrm{S}_{5}$, tem-se exemplos de descrições feitas pelos sujeitos para o movimento de uma bola em um campo aberto.

$\mathrm{S}_{4}$ : Então a bola, cê empurra, ela continua o movimento até um certo tempo, depois ela volta a parar de novo. E: Você empurra a bola. Quando você tira a mão dela, ela continua em movimento? $\mathrm{S}_{5}$ : Continua. E: E no caso do livro? $\mathrm{S}_{5}$ : Continua só um pouco, a distância é mínima, continua muito pouco, pouquinho.

As expectativas geradas por qualquer pessoa acerca do movimento de quaisquer objetos, giram em torno do fato de que eles sempre param, ou quase imediatamente como é o caso do livro, ou após um certo tempo como é o caso da bola. Para uma pessoa cega, suas observações do movimento de uma bola são limitadas, pois ela não vê o que ocorre com a bola quando esta está rolando livremente num campo aberto. Contudo, uma boa parte de suas experiências indicam que objetos devam parar e não continuar a se mover, e provavelmente isto possa ter levado $S_{4}$ e $S_{5}$ a fazer uma generalização acerca da duração do movimento da bola.

Em um outro trecho selecionado da entrevista de $S_{5}$, o sujeito descreve o mesmo fenômeno, no entanto, sua descrição apresenta os motivos pelos quais a bola continua a mover-se depois de alguém tê-la chutado, bem como, os motivos pelos quais ela pára após percorrer uma certa distância.

$\mathrm{E}$ : A força que você aplica na bola, permanece na bola? $\mathrm{S}_{5}$ : ... esta questão é meio complicada pra te dizer, eu não consigo colocar com uma precisão, porque você dá um impulso, ela sai com uma certa força, chega uma certa altura ela pára, aquele impulso não é suficiente pra continuar, 
agora, se a força foi junto, eu acho que não, não sei, é estranho... Nunca tinha pensado nisso antes. Ela pára porque ela perdeu a força, agora se a força foi junto eu não sei, é gozado...

Embora seus argumentos passem pelas expressões "dar um impulso", "aquele impulso não é suficiente para ela continuar" e "ela pára porque ela perdeu a força", é estranho para $\mathrm{S}_{5} \mathrm{O}$ fato da força ir junto com a bola, o que para qualquer teorista de impetus era motivo fundamental à continuidade do movimento. Portanto, as concepções alternativas dos sujeitos cegos para o movimento de objetos como o de uma bola, detêm analogias com o conceito ou idéia de força impressa de Hiparco/Filoponos e com a teoria do impetus de Buridan e seus seguidores.

O grupo de concepções alternativas $\mathrm{C}_{8}, \mathrm{C}_{9}, \mathrm{C}_{10}$, exibe uma característica em comum, $\mathrm{o}$ conceito de que objetos sólidos próximos à superfície da Terra, têm a tendência natural de cair. Propriedades como "a queda é algo natural", "os objetos caem pois não há nada que os segure", "quanto mais pesado, menor o tempo de queda", "o peso ou gravidade é uma propriedade intrínseca dos objetos, ou uma tendência que os objetos têm de cair em lugar de uma atração gravitacional exercida pela Terra", são características dominantes neste tipo de concepção.

As concepções alternativas $\mathrm{C}_{13}$ e $\mathrm{C}_{29}$, referem-se respectivamente à trajetória de esferas que abandonam tubos encurvados e retos e à trajetórias de esferas que se desprendem de um barbante que as fazia girar. Nelas pode-se encontrar uma semelhança com a generalização do conceito de impetus feita por seguidores de Buridan. Alguns teoristas do impetus, a fim de explicarem o movimento de uma roda e a continuidade do movimento das esferas celestiais ao redor da Terra, postularam uma vertente da teoria de força impressa, isto é, um impetus circular. No experimento, pediu-se para que os sujeitos descrevessem a trajetória de uma esfera após abandonar dois tipos de tubos, um reto e um encurvado, e também para descreverem a trajetória de uma esfera após se desprender de um barbante que a fazia girar (situação-4), e embora não fossem concepções alternativas unânimes, tais concepções alternativas foram encontradas não apenas junto aos sujeitos cegos, mas também, por McCloskey (op. cit.), junto a indivíduos videntes.

Por outro lado, a concepção alternativa, $\mathrm{C}_{20}$, foi classificada como: discordante da teoria de impetus. Em $\mathrm{C}_{20}$, verificou-se que a ausência de visão interfere de maneira significativa, pois $S_{1}$ e $S_{2}$, sujeitos que a expressaram, embora ouvissem o impacto da esfera com o solo, nunca foram capazes de ver que no caso específico desta experiência - uma esfera amarrada a um barbante girando sobre a cabeça - a trajetória descrita pela esfera quando o fio se rompe, é diferente da retilínea de cima para baixo. Em nenhum momento $S_{1}$ e $S_{2}$ mencionaram 0 deslocamento horizontal da esfera, para eles, a esfera deveria cair exatamente na vertical e sobre sua cabeça.

Já em $\mathrm{C}_{33}$, concepção alternativa expressa apenas por $\mathrm{S}_{4}$, encontrou-se uma descrição um pouco mais completa da trajetória da esfera, pois esse sujeito descreve o deslocamento horizontal da mesma. Coincidentemente ou não, $\mathrm{S}_{4}$ é um dos dois sujeitos que não nasceram cegos, pois perdeu a visão aos três anos, no entanto, entre os sujeitos que participaram da experiência de girar um barbante amarrado a uma esfera sobre sua cabeça, foi o único que descreveu o deslocamento horizontal da esfera quando o barbante é solto. 
A concepção alternativa $C_{41}$, expressa apenas por $S_{3}$, chamou a atenção de uma maneira especial pelo fato de que a justificativa empregada pelo sujeito para esta concepção, envolveu uma experiência vivida por ele em particular. $S_{3}$ afirmou que a trajetória de uma esfera ao abandonar um cano, seja ele reto ou curvo, seria aleatória, a não ser que houvesse paredes paralelas à esfera que a fizesse seguir a trajetória retilínea. Tal analogia foi empregada por $\mathrm{S}_{3}$, já que ele comparou a trajetória da esfera com a sua trajetória em um lugar aberto, sem paredes para que ele pudesse apoiar as mãos, como no caso de um corredor. Pelo fato de $\mathrm{S}_{3}$ só conseguir andar em linha reta apoiando suas mãos nas paredes paralelas de um corredor, tal concepção foi generalizada por ele para o caso da bola, e portanto, como $\mathrm{S}_{3}$ se sente totalmente perdido em um lugar aberto, e consequentemente se move segundo uma trajetória aleatória, a esfera ao abandonar canos de acordo com sua opinião, deveria ter o mesmo comportamento.

E: Você tem em sua frente dois canos, um reto e um encurvado. Se você colocar uma bolinha de aço deste lado do cano reto e empurrar, onde ela vai parar? $\mathrm{S}_{3}$ : Talvez ela para ai, mas é muito comprido pra ela ir. Será que ela não entala no meio?

E: Quando a bolinha sair do tubo reto, que tipo de caminho ela vai fazer? $\mathrm{S}_{3}$ : Ah, eu acho que ela não vai continuar reto, não tem nada nem aqui, nem aqui... (como, ripas paralelas). Que nem eu, as vezes eu fico perdida quando eu entro num lugar com bastante parede ai de repente vira um lugar bem assim, ai eu não sei se eu vou pra um lado ou pro outro, quando eu to no corredor, eu sei ir reto. Mas isso é porque eu penso, mas a bolinha não pensa, mas mesmo assim, eu acho que é quase a mesma coisa.

Por tanto, as concepções alternativas referentes à trajetórias de esferas, apresentaram razoáveis convergências à teoria de impetus circular, contudo, demonstraram ser novas do ponto de vista de experiências sensoriais e dessa forma, ficou evidente as dificuldades que os sujeitos tinham para emitirem opiniões sobre esse tema.

\section{VI- Conclusões:}

Neste texto, enfocou-se sob aspectos históricos e visuais, as concepções alternativas sobre repouso e movimento, de um grupo de seis sujeitos cegos. Verificou-se que para 0 referido grupo, existem tendências de suas concepções convergirem aos modelos précientíficos de movimento. Como apontam várias pesquisas nesta área, tais tendências também são verificadas junto a sujeitos videntes e portanto, indivíduos embora cegos, não representam exceção à maneira alternativa de como o senso comum aborda questões relacionadas ao tema aqui discutido.

Deste fato, a construção de concepções alternativas relacionadas com o movimento e o repouso dos objetos feita por qualquer pessoa, não parece depender exclusivamente de aspectos visuais, embora estes, sejam de fundamental importância na interação do homem com o meio físico, já que sensações auditivas e táteis participam de modo relevante na construção de tais concepções. Estes aspectos, deveriam ser levados em conta por professores de Física que trabalham com alunos cegos ou videntes, na construção de seu conhecimento científico pela superação de suas concepções alternativas. De acordo com os resultados obtidos, ao se excluir a observação visual de um indivíduo, suas concepções alternativas de repouso e movimento, praticamente não se alteram, fato que conduz a conclusão de que além da 
influencia social, observações não visuais participam diretamente na construção de concepções de repouso e movimento, e dessa forma, atividades de ensino baseadas em experiências táteis e auditivas, podem tornarem-se extremamente significativas ao ensino de Física de pessoas cegas, e por que não dizer, de pessoas que não sejam cegas.

De acordo com Lowenfeld, (1983) alguns princípios gerais descritos abaixo, devem ser definidos para se adaptar o ensino às necessidades educacionais do aluno cego.

Solidez: O conhecimento do sujeito cego é construído principalmente através da audição e do tato. Segundo esse autor, para que o aluno deficiente visual realmente compreenda 0 mundo ao seu redor, os professores devem apresentar-lhe, objetos que possam ser tocados e manipulados. Através da observação tátil, o aprendiz pode conhecer formas, sentir a atração gravitacional exercida pela Terra sobre objetos, a solidez, as qualidades de superfície, a maleabilidade, trocas de calor, entre outras.

Unificar experiências - A experiência visual tende a unificar o conhecimento em sua totalidade. Um indivíduo cego não consegue obter essa unificação, a não ser que os professores lhe apresentem experiências como "unidades de experiência". É necessário que o professor ponha "os todos" em perspectiva através da experiência concreta real e tente unificálas por meio de explicações e de seqüências.

Aprender fazendo: Para que o aluno cego aprenda a respeito do ambiente é necessário iniciá-lo na auto-atividade. Lowenfeld (op. cit.) sugeriu que, como a visão domina uma boa parte dos estágios da aprendizagem, que representa a base para muitos dos processos intelectuais superiores, torna-se importante oferecer alguma programação sistemática de experiências não visuais para as pessoas cegas.

Sob a abordagem do ensino de fenômenos relacionados ao repouso e ao movimento dos objetos, tais princípios não devem necessariamente ser aplicados somente a alunos cegos, já que a consciência do "estar em movimento", bem como as características das concepções alternativas relacionadas a este tema, não são exclusividade dos videntes. A introdução de situações problemas ao ensino de Física, que envolvam observações auditivas e táteis, de fenômenos relacionados a repouso e movimento, pode gerar conflitos que façam com que o aluno questione suas concepções alternativas. Através da adaptação e/ou da criação de atividades de ensino de Física à pessoas cegas, pessoas videntes podem se aproveitar dessas atividades e a partir disso, obter uma melhor compreensão ou mesmo alterar suas concepções alternativas de repouso e movimento.

Desta forma, é sugerida uma abordagem positiva da questão da deficiência visual, isto é, a cegueira, além de representar uma barreira social, que pode e deve ser superada, tanto por parte do deficiente, quanto por parte da sociedade, deve ser encarada como algo que desperte a consciência de todos os educadores para a importância de experiências não visuais na construção de suas atividades de ensino

Agradecimentos: Os autores agradecem à FAPESP pelo apoio financeiro e ao Lar Escola Santa Luzia para Cegos, que permitiu a realização das entrevistas com os sujeitos.

\section{VII- Referências bibliográficas:}


BAUGHMAN, J.; ZOLLMAN, D. Physics labs for the blind. - The physics teacher, p. 339-342, 1997.

BROWN, D. E.; CLEMENT, J. Misconceptions concerning Newton's law of action and reaction: The underestimated importance of the third law. In: Novak J. D. (ed.), Proceedings of the second International Seminar on Misconceptions in Science and Mathematics, Cornell University, 1987,v. III, p. 39-53,

CAMARGO, E. P. Um estudo das concepções alternativas sobre repouso e movimento de pessoas cegas. Bauru: UNESP - Universidade Estadual Paulista "Júlio de Mesquita Filho", Faculdade de Ciências, 2000. (Dissertação, Mestrado em Educação para a Ciência) 218 p.

CARVALHO, A.M.P., Construção do Conhecimento e Ensino de Ciências. Em Aberto, v.11, n.5, p. 9-16, 1994.

CLEMENT, J. Cognitive development project working paper. University of Massachusetts, Amherst, 1979.

CLEMENT, J. Students preconceptions in introductory mechanics. American Journal Physics, 1982. v. 50, p 66.

COHEN, I.B. A Física de uma Terra em movimento. In: (Ed.) O nascimento de uma nova

Física. São Paulo: Livraria Editora. 1967, Cap. 1, p. 1-27.

DRIVER, R. Students' Conceptions and the Learning of Science. International Journal of Science Education, v. 11(special issue), p. 481-490, 1989.

DUIT, R., GOLDBERG, F. e NIEDDERER, H. (Ed.). Research in Physics Learning: Theoretical Issues and Empirical Studies. Proceedings of an International Workshop held at the University of Bremem. Bremem, Institut Für die Pädagogik der Naturwissenschaften an der Universität Kiel. 1991.

ECKSTEIN, S. G. e SHEMESH, M. Stage Theory of the development of alternative conceptions. Journal of research in science teaching. v. 30, n. 1. p. 45-64. 1993.

FRANKLIN, A. Inertia in the middle ages. The Physics Teacher. v. 16, n. 4, p. 201-208, 1978.

GARDNER, P. L. Physics students' comprehension of motion with constant velocity - The Australian science teachers. v. 31, n.4, p. 27-32, 1986.

GUNSTONE, R.F., WHITE, R.T. e FENSHAM, P. Developments in Style and Purpose of Research on the Learning of Science. Journal of Research in Science Teaching, v. 25, p. 513529, 1988

HALLOUN, I. A., HESTENES, D. Common sense concepts about motion. American Association of Physics Teachers. p. 1056-1065, 1985.

HISE, Y. V. Student Misconceptions in Mechanics: An International Problem? The Physics Teacher. p. 498-502, 1988.

KOYRÉ, A. Aristóteles. In: __ (Ed.) Estudos Galilaicos. Lisboa: Publicações Dom Quixote. 1986, p.22-23.

LEMEIGNAN, G.; WEIL-BARRAIS, A. W. A developmental approach to cognitive change in mechanics. International Journal of Science Education. v. 16, n. 1, p. 99-120, 1994.

LINN, M. C., THIER, H. D. Adapting science material for the blind (ASMB): Expectation for student outcomes. Science Education v. 59, p. 237-246, 1975. 
LOCHHEAD, J.; DUFRESNE, R. Helping students understanding difficult science concepts through the use of dialogues with history. The History and Philosophy of Science in Science Teaching. 1989. p. 221-229

LOWENFELD, B. Berthold Lowenfeld on Blindness and Blind People: Selected Papers. New York: American Foundaton for the Blind, 1983

MASINI, E. F. S. O perceber e o relacionar-se do deficiente visual; orientando professores especializados. Revista Brasileira de Educação Especial. p. 29-39, 1990.

McCLOSKEY, M., CARAMAZZA, A., GREEN, B. Curvilinear motion in the absence of external forces: Naive beliefs about the motion of objects. Science v. 210, p. 1139-1141, 1980.

McDERMOTT, L.C. What we Teach and What is Learned - Closing the Gap. American Journal of Physics, n. 59, p. 301-315, 1991.

MINSTRELL, J. Explaining the "at rest" condition of an object. The Physics teacher. p. 10- 14, 1982.

PEDUZZI, L. O que é a Física Aristotélica: Por que não considerá-la no ensino da mecânica? Caderno Catarinense de Ensino de Física, Florianópolis, v. 13, n.1, p. 48-63, 1996.

POSNER, G. J. et al. Accommodation of a specific conception: towards a theory of conceptual change. Science Education. v. 66, n. 2, p. 211-227, 1982.

ROBIN, N. \& OHLSSON, S. Impetus then and now: A detailed comparison between Jean Buridan and a single contemporary subject. The History and Philosophy of Science in Science Teaching. 1989. p. 292-305.

SANTOS, M.E.V. Mudança Conceitual na Sala de Aula. Lisboa, Livros Horizonte. 1991.

SEVILLA, J., et al. Physics for blind students: a lecture on equilibrium. Physics Education v. 26, p. 227-230, 1991.

SILVA, D. e LATTOUF, R. Eletricidade: Atividade de Ensino Coerente com um Modelo Construtivista. Pro-posições, Campinas SP. 1996

SILVA, S. C. Deficiência Visual e Identidade: Uma Construção Cognitiva - Revista Álvares Penteado, São Paulo, v. 2, n. 5, p. 113 - 127, 2000.

STINNER, A. The story of force: from Aristotle to Einstein. Physics education. p. 77-85, 1994

TWIGGER, D., et al. The conception of force and motion of students aged between 10 and 15 years: an interview study designed to guide instruction. International Journal of Science Education. v. 16, n. 2, p. 215-229, 1994.

VILLANI, A. Conceptual Change in Science and Science Education. Science Education, v. 76, n.2, p. 223-237, 1992.

WATTS, D. M. A study of school children' $s$ alternative frameworks on the concept of force. European journal of science education. v. 5, n. 2, p. 217-230, 1983.

WEENS, B., A physical science course for the visually impaired. The physics teacher, p. 333338, 1977. 